\title{
Primary malignant lymphoma of the uterus
}

\author{
H. FOX AND J. R. S. MORE \\ From the Departments of Pathology and Obstetrics, University of Manchester, and the \\ Department of Pathology, St. Mary's Hospital, Manchester
}

SYNOPSIS The clinical and pathological findings in a 59-year-old woman with a primary malignant lymphoma of the corpus uteri are described. There was a period of eight months between detection of the uterine lesion and evidence of disease elsewhere in the body. The patient died of disseminated lymphoma, and the distribution of secondary deposits were suggestive of spread via the right ovarian-uterine venous system.

The criteria for acceptance of a diagnosis of primary uterine lymphoma are discussed and the previous literature is reviewed. There have been nine acceptable cases of primary uterine lymphoma recorded: four in the corpus uteri and five in the cervix. The differential diagnosis from stromal sarcoma, anaplastic endometrial adenocarcinoma, leiomyosarcoma, and benign lymphoid hyperplasia is discussed.

Primary extranodal malignant lymphoma is not uncommon and can occur in a wide variety of organs (Gall and Mallory 1942; Rosenberg, Diamond, Jaslowitz, and Craver, 1961). Primary lymphoma of the uterus is, however, extremely rare and only nine acceptable cases have been recorded in the literature. In only four of these did the lymphoma arise in the corpus uteri; in the remaining five cases the lymphoma was limited to the cervix.

In this paper a further case of primary malignant lymphoma of the corpus uteri is reported.

\section{CASE REPORT}

A 59-year-old woman was first seen at St. Mary's Hospital, Manchester, in February 1964. Her menopause had occurred in 1958 and she had been well until two weeks previously when she had developed pain in her hips and back. Two days later she noticed vaginal bleeding, and this had persisted for one week.

Physical examination showed a healthy looking woman. She did not appear anaemic, her skin was normal, and there was no lymphadenopathy. No abnormality was found in the thorax or in the nervous system. On abdominal examination there was no enlargement of the liver or spleen but there was a mass arising from the pelvis. This was about the size of a 16-week pregnancy. On vaginal examination the vulva, vagina, and cervix were normal: a large irregular mass was felt which appeared to be attached anteriorly to the uterus. The adnexae were normal.

Laparotomy was performed in March 1964 and a large fibroid tumour was found arising from the right

Received for publication 30 March 1965. lateral aspect of the uterus. A hysterectomy and bilateral salpingo-oophorectomy was carried out.

PATHOLOGICAL EXAMINATION OF THE REMOVED SPECIMEN The uterus measured $12 \mathrm{~cm}$. from apex to os, $6 \mathrm{~cm}$. from side to side, and $4.5 \mathrm{~cm}$. in the antero-posterior plane. Attached to the uterus on its right lateral aspect was a fibroid tumour measuring $12 \times 8 \times 9 \mathrm{~cm}$. Its cut surface had the typical white, firm, whorled appearance. On sectioning the uterus, there was a soft yellowish tumour mass that appeared to be largely replacing the endometrium and widely infiltrating the myometrium (Fig. 1). The tumour mass was moderately well demarcated from adjacent healthy tissue. The tumour involved mainly the posterior uterine wall where it extended from the fundus to within $1.5 \mathrm{~cm}$. from the internal os, but it also extended over the fundus, into the left isthmic region, and (to a lesser extent) into the anterior and lateral uterine walls. The cervix appeared macroscopically normal as did the tubes and ovaries.

Histologically the fibroid tumour was a leiomyoma with extensive hyaline change, and showed no evidence of malignancy. The uterine tumour was composed principally of lymphocytic cells (Fig. 2). In some areas the predominant cell was a well-differentiated mature small lymphocyte but in others there was a mixture of well-differentiated and primitive lymphocytic cells, the primitive lymphocytic cells having a large nucleus with a prominent nuclear membrane, well marked nucleoli, scanty cytoplasm and somewhat indistinct cell margins. Occasional mitotic figures were seen. The endometrium was stretched over the tumour which appeared to have originated in the deepest layers of the endometrium. The endometrium was atrophic with occasional cystically dilated glands. The endometrial stroma was diffusely infiltrated by lymphocytic cells which were in direct 


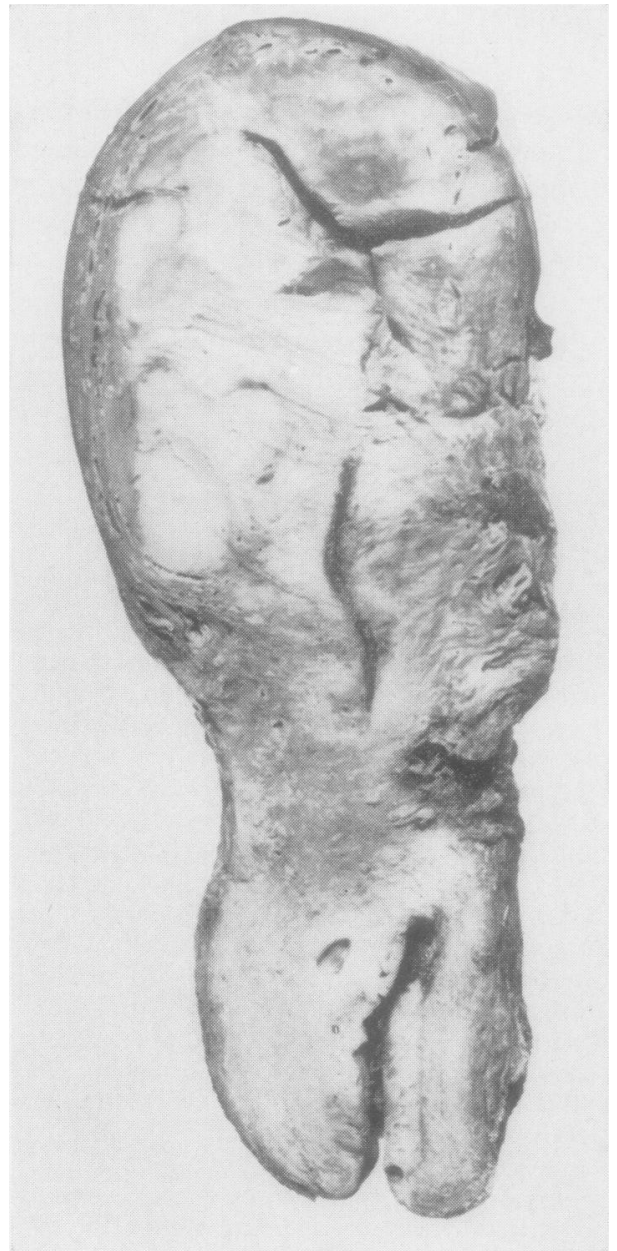

FIG. 1. Cut surface of uterus. The pale tumour mass is moderately well demarcated from the surrounding tissue.

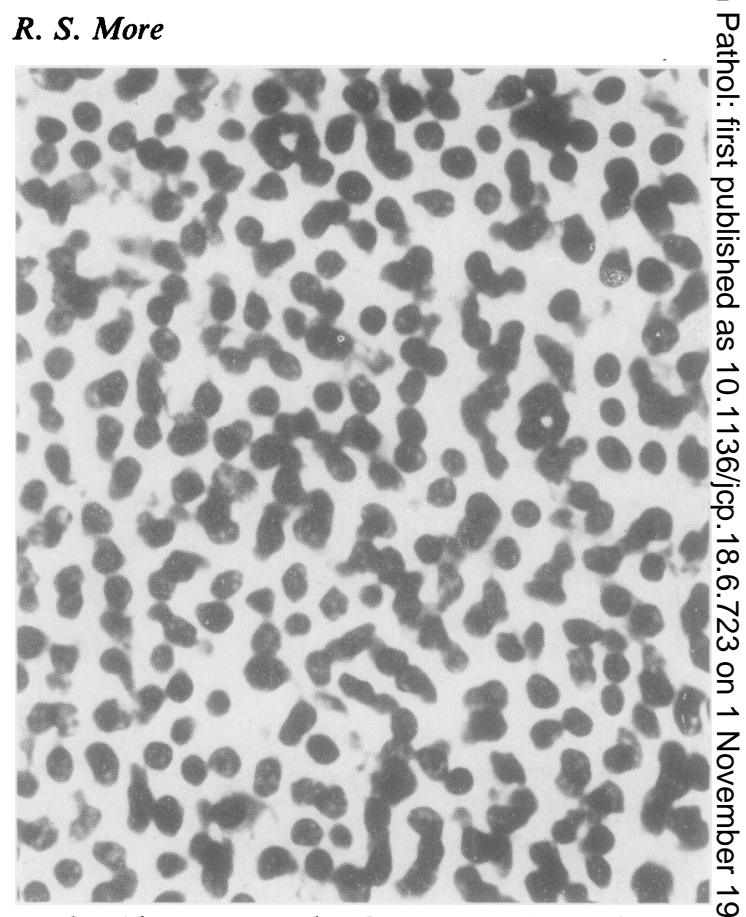

FIG. 2. Photomicrograph of tumour. The predominanto cell in this area is a mature small lymphocyte. (Haematoxylin and eosin $\times 850$.)

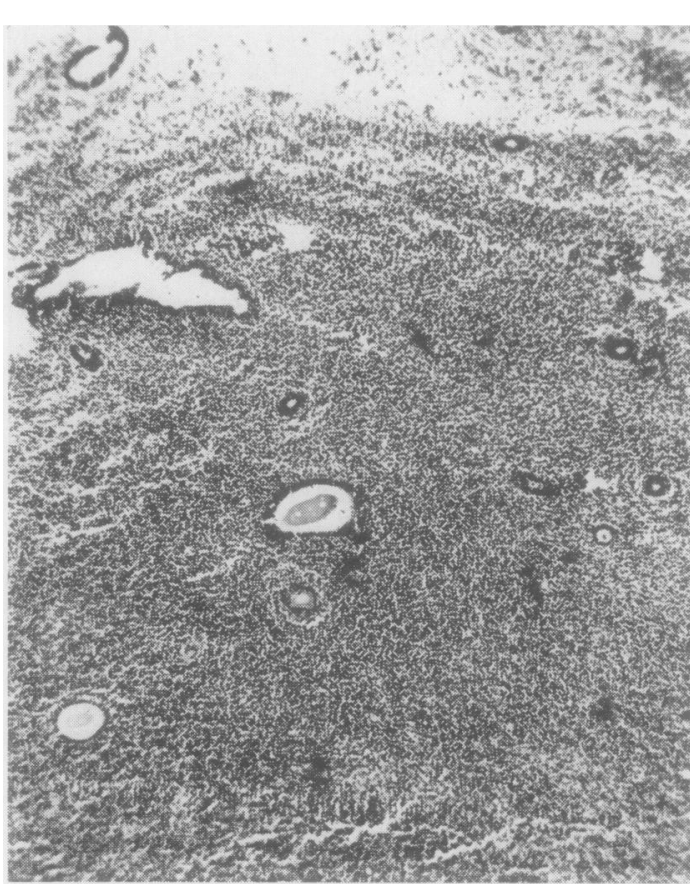

FIG. 3. Photomicrograph of endometrium. The endo- $\triangle$ metrial glands are surrounded, and widely separated, $b v \overrightarrow{\mathrm{D}}$ tumour cells. (Haematoxylin and eosin $\times 150$.) 


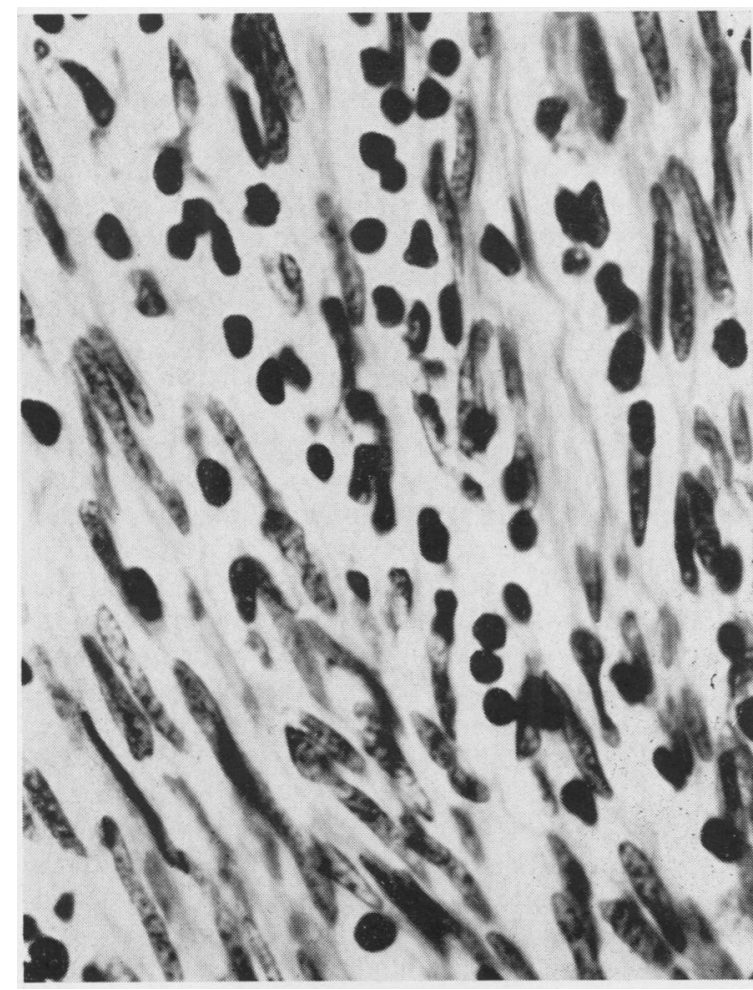

FIG. 4. Photomicrograph of myometrium adjacent to tumour mass. Tumour cells are infiltrating between the muscle fibres. (Haematoxylin and eosin $\times 850$.)

continuity with the tumour (Fig. 3). Thus, the endometrial glands were embedded in, and widely separated by, tumour, but were themselves intact and normal. Similarly tumour cells were infiltrating out into the myometrium (Fig. 4) between the muscle fibres, often separating them quite widely.

The cervix showed a little non-specific chronic inflammation with epidermidization and reserve cell hyperplasia in the endocervix. There was no evidence of lymphomatous tumour in the cervix. The ovaries were atrophic but were otherwise normal as were the Fallopian tubes.

PROGRESS OF PATIENT The patient's post-operative recovery was uneventful and the wound healed normally. In view of the histological findings a chest radiograph, radiograph of the spine, a full blood count, and sternal marrow examination were performed. All were normal. It was thought that there was no evidence of residual disease but nevertheless the patient was given a course of cytotoxic drugs.

The patient remained in good health for a further eight months until December 1964, when for the first time, the liver was palpable., she appeared tired, ill, and anaemic. Thereafter deterioration in her condition was rapid and she died at home in January 1965, five weeks after the first indication of hepatomegaly.
NECROPSY The skin was jaundiced and there were numerous petechial haemorrhages. The thyroid contained many adenomatous nodules but otherwise the head and neck organs were normal. The thoracic organs were also normal though the left pleural cavity contained $250 \mathrm{ml}$. of clear fluid. The peritoneal cavity contained $1,200 \mathrm{ml}$. of clear yellow fluid and the liver contained numerous nodules of tumour tissue varying in size up to $8 \mathrm{~cm}$. in diameter. These nodules were rubbery, pinkish-white, and showed haemorrhagic mottling. Four similar nodules, each $1 \mathrm{~cm}$. in diameter, were present in the substance of the right kidney. There was a plaque of tumour tissue on the under surface of the right leaf of the diaphragm and a similar plaque was present in the connective tissue adjacent to the superior border of the right adrenal gland. This plaque of tumour was showing early invasion of the adrenal gland. The remaining abdominal viscera were normal and, in particular, the spleen was not enlarged. The pelvis was macroscopically free of tumour but the right ovarian vein contained an old thrombus $3 \mathrm{~cm}$. in length. One or two lymph nodes in the right para-aortic chain were slightly enlarged but the nodes elsewhere in the body appeared normal. Histologically the tumour deposits in the diaphragm, liver, right adrenal area, and right kidney all showed an appearance similar to the original uterine tumour. Similar tumour was present in the right para-aortic lymph nodes, which showed complete loss of their normal lymphoid follicular pattern and replacement by tumour. Tumour was also present histologically as a diffuse infiltration of the peritoneum of the pelvic floor and anterior wall of the rectum. The multiple nodules in the thyroid were microfollicularadenomata and there was no evidence of thyroid lymphoma. Sections of thrombus in the right ovarian vein showed numerous malignant cells similar in appearance to those of the original tumour. These were embedded deeply in the thrombus. The remaining organs showed no histological abnormality.

FINAL DIAGNOSIS This was established as primary malignant lymphoma of the uterus with eventual metastasis to the liver, right kidney, and right leaf of the diaphragm, and tumour thrombus in the right ovarian vein. The curious localization of the secondary deposits in the right side of the abdomen suggested that metastasis had occurred via the right ovarian-uterine venous network.

\section{DISCUSSION}

Involvement of the female genitalia by malignant lymphoma can be classified into several patterns (Ober and Tovell, 1959): (1) established malignant lymphoma in which secondary manifestations occur in the female genitalia; (2) asymptomatic leukaemic infiltration of the female genitalia; (3) generalized malignant lymphoma in which involvement of the female genital tract is part of the presenting clinical picture; (4) initial localization of a tumour mass in the female genital tract, the apparent primary site of extranodal lymphoma. 
The incidence of the first three groups in any series of malignant lymphomata depends to a large extent upon the assiduity with which involvement of the female genitalia is sought, both clinically during life and pathologically at necropsy. It is not therefore surprising that the reported incidence varies considerably from series to series. Hahn (1958) found evidence of genital involvement in $4 \%$ of a group of 742 cases of lymphoma. Sugarbaker and Craver (1940) found only one case of genital involvement in 196 cases of lymphoma; Jackson and Parker (1947) reported involvement in three out of 59 cases and Naumann (1947) in three out of 86 cases. Rosenberg et al. (1961), in their review of 1,269 cases of malignant lymphoma, found clinical involvement of the female genital tract in only five cases. In patients coming to necropsy, however, they found that the genital tract was histologically involved in nearly $40 \%$ of their series.

It is the fourth group, namely, primary malignant lymphoma of the female genital tract, that is the particular concern of this paper. In a disease that may be initially uni- or multifocal it is necessary to define criteria for diagnosis of primary extranodal lymphoma and we have only accepted cases as true primary uterine lymphoma if (1) at the time of initial diagnosis the disease process was clinically confined to the uterus; (2) full investigation failed to reveal any evidence of disease elsewhere in the body; (3) the blood count showed no evidence of leukaemia; and (4) if further lymphomatous deposits occurred at sites removed from the genital tract then a time interval of at least several months should have elapsed between the appearance of primary and secondary tumours.

With the application of these criteria the number of acceptable cases of primary uterine lymphoma is very small. Thus, the cases described by Willschanin (1879), Wagner (1902), Lerchenthal (1904), Schlagenhaufer (1911), and Walther (1934) must all be rejected, either because of a lack of clinical or pathological details or because there was widespread lymphomatous disease involving many organs at the time of initial diagnosis. Similarly two cases reported by Russo (1953), the first being that of a 48-year-old woman with a reticulum cell sarcoma of the cervix, and the second that of an 80-year-old woman with a histiocyto-sarcoma of the cervix, also lack proof of primary origin in the uterus, for full clinical details are not given, there was no follow-up, and necropsy was not performed. Tesluk and Topp (1958) described a lymphosarcoma of the uterus in a 35-year-old woman. The patient was otherwise well but re-examination of malignant tissue (previously considered as carcinomatous) removed from a maxillary sinus two years previously showed this also to be lymphosarcoma, and hence this case is actually one of primary lymphoma of $\underset{\vec{S}}{\vec{*}}$ the maxillary antrum. Burrows, Hosten, and Pomerantz (1964) have recently reported a patient of 65 듬 with lymphosarcoma of the uterus. This diagnosis $\frac{\bar{\sigma}}{2}$ was established by biopsy but the patient died im- $\bar{\Phi}$ mediately afterwards and at necropsy was found to have widely disseminated lymphosarcoma. The uterine tumour was the largest single tumour but $\vec{\circ}$ this alone does not necessarily indicate that this was $\overrightarrow{\vec{A}}$ the primary site of the lesion, and hence the case ${ }^{\omega}$ must be considered unproven.

There appear to be only nine recorded cases which? fulfil the criteria outlined above for the diagnosis $\vec{\infty}$ of primary uterine lymphoma. Epperson (1950) reported a 42-year-old woman with menorrhagia $N$ and pelvic pain. The uterus was enlarged and the 0 cervix nodular and ulcerated. Curettings and cervical $\underset{ }{\longrightarrow}$ biopsy were reported as showing anaplastic carcin- $z$ oma. The patient died three months later with widespread dissemination of a reticulum cell sarcoma, $\frac{\Phi}{3}$ and review of the biopsy specimen showed that the original uterine tumour was also a reticulum cell sarcoma. Walton (1953) reported two cases, the $\vec{\oplus}$ first a woman of 36 with menorrhagia. The uterus or was enlarged but the patient was otherwise well and all investigations were negative. Hysterectomy was performed and diffuse nodular thickening of the endometrium due to lymphosarcomatous infiltration was found. The patient was well at the time of this report but the length of follow-up is not indicated. His second patient was aged 88 and presented with bloodstained vaginal discharge. A cervical tumour $\frac{J}{J}$ was present which proved histologically to be a lymphosarcoma. There was no evidence of disease elsewhere, the patient was treated by irradiation, and remained well for three and a half years untilo she died of pneumonia complicating a fractured femur. Johnson and Soule (1957) reported a case of $ᄋ$ a 49-year-old woman who complained of vaginal discharge. The cervix was grossly enlarged and both the cervical biopsy and endometrial curetting showed $\supset$ a lymphosarcoma. After treatment with radiation the patient remained well and four years later was quite fit with no evidence of disease elsewhere. $A$. further two cases have been reported by Ober and $\mathbb{O}$ Tovell (1959). The first patient was aged 44 and com- స్తు plained of lower abdominal pain. The uterus was enlarged, as was the cervix which bled profusely once touch. The uterine enlargement was due to multiple leiomyomata but the cervical neoplasm was histologically a reticulum cell sarcoma. The patient was 0 treated by hysterectomy and irradiation and was

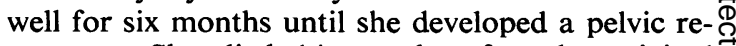
currence. She died 14 months after the original $\stackrel{\mathbb{Q}}{\mathcal{Q}}$ diagnosis from disseminated reticulum cell sarcoma 
involving many organs. Their second patient, aged 47, complained of menorrhagia and the uterus was found to be enlarged. There was no other abnormality. Hysterectomy was performed and an intramural mass $5 \mathrm{~cm}$. in diameter was found in the left cornual area. Histologically this was a reticulum cell sarcoma. The patient died seven months later of widely disseminated reticulum cell sarcoma. Welch and Hellwig (1963) reported a 47-year-old patient with a reticulum cell sarcoma apparently confined to the cervix. The cervix was irradiated and the patient was alive and well two years later. Retikas (1960) and Nasiell (1964) have each described cases of Hodgkin's disease confined to the cervix. Nasiell's patient was alive and well eight months after irradiation and hysterectomy, and Retikas' patient was well and free from disease at the time of his report.

The case report in this paper appears therefore to be the tenth such recorded that satisfies the criteria for primary uterine lymphoma.

Throughout this paper the term 'lymphoma' has been used. Although it is true that in many cases a clear distinction can be drawn between lymphosarcoma and reticulum cell sarcoma, the tumour in the case reported here shows varying features in different areas which could be interpreted either as reticulum cell sarcoma or lymphosarcoma. Gowing (1964) has said of tumours of this type that 'the distinction between poorly differentiated neoplastic lymphocytes and reticulum cells is often impossible or arbitrary and the cytological picture is often very pleomorphic within a single tumour'. It is felt that this remark applies to the tumour described in this paper and hence the relatively noncommittal term 'malignant lymphoma' has been used.

Primary lymphoma may occur elsewhere in the female genital tract outside the uterus. A few cases have been reported in the ovary (Nelson, Dockerty, Pratt, and ReMine, 1958; Collins and Piper, 1962; Sirsat and Amin, 1963), and in the vulva (Bickel and Bennett, 1954; Buckingham and McClure, 1955; Weseley and Berrigan, 1958). The paucity of cases in the ovary is explicable by the absence of lymphoid tissue in this organ but this explanation will not suffice for the rarity of the condition in the uterus, since lymphoid follicles are frequently present in the endometrium of healthy women, and possibly in the endometrium of all pre-menopausal women (Irwin, 1956; Payan, Daino, and Kish, 1964). The small number of documented cases may be partially due to the difficulties of histological diagnosis. A uterine lymphoma has to be differentiated from an anaplastic endometrial adenocarcinoma, from stromal endometriosis, and from a poorly differentiated leiomyosarcoma. The chief histological point of differentiation from all these lesions, apart from the cytology, is that the lymphoma is clearly an infiltration. Thus both in the case reported above and in most of the cases reported in the literature the tumour cells have been found diffusely infiltrating between and around normal endometrial glands. Similarly in the cervix, the tumour cells tend to infiltrate between normal endocervical glands, often separating them quite widely. A further lesion from which malignant lymphoma must be differentiated is benign lymphoid hyperplasia. Such a condition has been reported in the stomach (Faris and Saltzstein, 1964), rectum (Helwig and Hansen, 1951), and lungs (Saltzstein, 1963), and many cases of this condition have previously been considered to be malignant lymphoma. Although no example of this condition has been reported as such in the endometrium it seems highly possible that the primary endometrial lymphoma described by Irwin (1956) was such a case. The endometrium in this case contained a small polyp $1 \mathrm{~cm}$. in diameter. Microscopically the polyp contained lymphoid tissue showing well-marked germinal centres and a follicular pattern. Although this could possibly have been a case of localized follicular lymphoma, the accompanying illustrations suggest that benign lymphoid hyperplasia was the true diagnosis in this case; the author himself considered that the lesion was essentially benign.

We are indebted to Dr. F. A. Langley for his help and advice; to Mr. T. B. Fitzgerald for allowing us to quote the clinical details of the patient; to Professor W. I. C. Morris in whose department this paper was prepared; to the Department of Medical Illustration, Manchester Royal Infirmary, for Fig. 1, to Mr. B. W. Figg for the photomicrographs, and Dr. A. M. Calmonson for helping to arrange the necropsy.

\section{REFERENCES}

Bickel, D. A., and Bennett, J. R. (1954). Amer. J. Obstet. Gynec., 67, 1257.

Buckingham, J. C., and McClure, J. H. (1955). Obstet. and Gynec., 6, 138.

Burrows, S., Hosten, E. B., and Pomerantz, J. (1964). Ibid., 24, 468. Collins, J., and Piper, P. G. (1962). Ibid., 20, 686.

Epperson, J. W. W. (1950). West. J. Surg., 58, 701.

Faris, T. D., and Saltzstein, S. L. (1964). Cancer (Philad.), 17, 207.

Gall, E. A., and Mallory, T. B. (1942). Amer. J. Path., 18, 381.

Gowing, N. F. C. (1964). In The Pathology of Testicular Tumours (Brit. J. Urol., vol. 36, suppl.), edited by D. H. Collins and R. C. B. Pugh, pp. 1-94, Livingstone, Edinburgh and London.

Hahn, G. A. (1958). Amer. J. Obstet. Gynec., 75, 673.

Helwig, E. B., and Hansen, J. (1951). Surg. Gynec. Obstet., 92, 233. Irwin, J. B. (1956). Amer. J. Obstet. Gynec., 72, 915.

Jackson, H., and Parker, F. (1947). Hodgkin's Disease and Allied Disorders. Oxford University Press, London.

Johnson, C. E., and Soule, E. H. (1957). Obstet. and Gynec., 9, 149. Lerchenthal, R. (1904). Ueber Uterussarkom. (Inaug. Diss. Tübingen). Himmer, Augsburg.

Nasiell, M. (1964). Acta. cytol. (Philad.), 8, 16.

Naumann, H. N. (1947). Arch. Path., 43, 324.

Nelson, G. A., Dockerty, M. B., Pratt, J. H., and Re.Mine, W. H, (1958). Amer. J. Obstet. Gynec., 76, 861 . 
Ober, W. B., and Tovell, H. M. M. (1959). Bull. Sloane Hosp. Wom. N.Y., 5,65 .

Payan, H., Daino, J., and Kish, M. (1964). Obstet. and Gynec., 23, 570.

Retikas, D. G. (1960). Amer. J. Obstet. Gynec., 80, 1104.

Rosenberg, S. A., Diamond, H. D., Jaslowitz, B., and Craver, L. F. (1961). Medicine (Baltimore), 40, 31.

Russo, S. (1953). Arch. ital. Anat. Istol. pat., 26, 167.

Saltzstein, S. L. (1963). Cancer, (Philad.), 16, 928.

Schlagenhaufer, F. (1911). Arch. Gynäk., 95, 1.

Sirsat, M. V., and Amin, N. M. (1963). J. Obstet. Gynaec. India, 13, 426.
Sugarbaker, E. D., and Craver, L. F. (1940). J. Amer. med. Ass., 115. 112.

Tesluk, H., and Topp, W. L. (1958). Amer. J. Obstet. Gynec., 75, 156. 产 Wagner, G. A. (1902). Verh. Ges. dtsch. Naturforsche. Artze., 78, 264. Walther, O. (1934). Arch. Gynäk., 157, 44.

Walton, L. L. (1953). Conn. med. J., 17, 819.

Welch, J. W., and Hellwig, C. A. (1963). Obstet. and Gynec., 22, 293. Weseley, A. C., and Berrigan, M. V. (1958). Ibid., 11, 192.

Willschanin, P. (1879). Arch. G.vnäk., 14, 164. 